\title{
Managing irrigation under pressure: how supply chain demands and environmental objectives drive imbalance in agricultural resilience to water shortages
}

Chloe Sutcliffe, Jerry Knox* and Tim Hess

Cranfield University, Cranfield, Bedford MK43 OAL, UK

* Corresponding author: j.knox@cranfield.ac.uk

\begin{abstract}
Food production systems worldwide are increasingly exposed to water shortage shocks.

Social-ecological resilience theory provides insights into the qualities which confer production systems with the capacity to absorb shocks and persist, undertake adaptations and ultimately achieve desirable transformations. Combining findings from the analysis of a set of 15 semi-structured interviews and 92 survey responses from growers in the UK, this paper uses resilience theory to explore the factors affecting exposure to the risk of water shortages, and management responses, within outdoor field vegetable production systems that depend on supplemental irrigation. The findings confirm that growers predominantly aim to build resilience by seeking to maintain a buffer or 'headroom' in their water resources to minimise the possibility that a shortage will disrupt their output of marketable produce and/ or lead to financial loss. This buffering strategy confers robustness by increasing system redundancy (availability of spare resources). But building-in redundancy conflicts with regulatory and supply chain pressures to maximise water and production efficiency respectively. Whilst stability of supply to consumers is, for the most-part, achieved, the discrepant pursuits of robustness and efficiency lock agricultural systems into increasingly rigid production and sales pathways, limiting capacities for adaptation and transformation - dimensions of resilience which permit successful system evolution in the context of more extreme shocks and stresses.
\end{abstract}

Keywords: adaptation; drought; food; transformation; water resources 


\section{Introduction}

Water shortages constitute a key problem for global food security in the context of climate change and population growth (Hanjra and Qureshi, 2010), but it is unclear how resilience to the challenge of water shortages can be enhanced at the local scale for agricultural production. In the UK, domestic horticulture plays an essential role in providing over $90 \%$ of the staple vegetables (potatoes, carrots, onions, brassicas and beans) that support the food and nutritional security of the population (Defra, 2016; HMRC, 2017). Whilst water resources in some regions of the UK are abundant, in other parts of the country they are acutely limited. For example, nearly a third of the country's field vegetables (horticultural crops grown outdoors including potatoes) are grown in eastern England (Defra, 2018) where fertile soils, suitable climate and gentle topography provide ideal conditions for large-scale intensive production (Knox and Hess, 2018), but this area is also one of the most water stressed regions in the country (Knox et al., 2018). As such, supplemental irrigation is a critical component of UK field vegetable production (Rey et al., 2016).

In England and Wales summer water resources in many catchments are over-committed, with around $40 \%$ of agricultural holdings located in catchments defined as either 'over-licensed' and/or 'over-abstracted' (Hess et al., 2010). Water for irrigation is primarily abstracted direct from rivers and streams (54\%) with groundwater making up the remainder (41\%) (Defra 2011). All direct abstractions above a de minimis ( $20 \mathrm{~m}^{3} /$ day) are controlled by the water regulatory agency (Environment Agency (in England) and Natural Resources Wales), via time-limited licences which specify conditions for reducing abstractions when flows and/or groundwater levels fall below prescribed levels. Under severe drought conditions, the agency also have regulatory powers under the Water Resources act (1991) to ban abstractions, socalled "Section 57" restrictions. Although these are considered a last resort action, for many agribusinesses this remains their major irrigation risk. Ongoing reforms to reduce the environmental impacts of abstraction, and the volumes of water locked up in unused or under-used licences, are likely to further reduce allocations to irrigated agriculture (Knox et al., 2020).

Increased climate variability and a changing climate are also projected to increase the risk of low river flows (Brown et al., 2016) and increase the demand for irrigation (Knox et al., 2018). This means the risk of abstraction restrictions will likely become more frequent and protracted in future (Salmoral et al., 2019), heightening the exposure of production to water 
shortages, and potentially threatening the security and stability of food supplies to UK consumers.

Within this increasingly precarious context, it is essential that growers employ strategies to enhance the resilience of their production activities to the threat of water shortages.

Fundamentally, resilience refers to "an ability to recover from or adjust easily to misfortune or change" (Merriam-Webster, 2020). It involves the capacity not only to absorb shocks or stresses (robustness), but also to adapt and ultimately change course, if necessary, to a desirable alternative pathway. It is commonly considered to be measurable across three dimensions; the amount of change the system can undergo whilst still retaining the same "controls on structure and function"; "the degree to which the system is capable of selforganization" and "the degree to which the system can build capacity to learn and adapt" (Carpenter et al., 2001, p. 766). In this paper we represent these three dimensions via the qualities of robustness (or persistence), adaptability and transformability (Ashkenazy et al., 2018; Boltz et al., 2019).

Resilience has been widely adopted as normatively desirable and is often misused interchangeably with sustainability. However, normativity does not characterise the term's origins within pure ecology (Olsson et al., 2015), but derives from its application to social ecological systems, where sustainable resource provision for human wellbeing is a dominant concern. Whilst a sustainable system must be resilient, a resilient system is not necessarily sustainable (Boltz et al., 2019), highlighting that resilience may infer persistence of a system state that is not desirable from a human perspective - variously referred to as 'negative resilience' or a 'rigidity trap' (Allison and Hobbs, 2004).

Set within a context of growing concerns regarding the availability and reliability of water to support food crop production and widespread discourse around concepts of resilience, this paper critically evaluates UK field vegetable grower perspectives on the factors that determine the resilience of their production systems to drought and water shortages. The analysis identifies how the factors and responses discussed by growers impact the resilience dimensions discussed above, and the consequences for catchment water management and fresh produce supply chains.

\section{Materials and methods}

We used a mixed methods approach to identify how managers of field vegetable growing enterprises conceptualise (and undertake strategies intended to build) the resilience of their 
production systems to water shortages. Qualitative data from a series of semi-structured interviews were combined with quantitative data from an online survey. The use of mixed methods delivers a nuanced understanding of how growers determine their irrigation management decisions (based on the qualitative data), whilst permitting extrapolation (via triangulation with quantitative findings) to a broader population.

\subsection{Key informant interviews}

In November 2018 a total of 32 growers were identified, either by their business's web pages, or from previous contact with the research team, and were contacted via an email explaining the research and asking if they would be willing to participate in an interview. The only selection criterion was experience of managing the use of supplemental irrigation for the commercial production of field vegetables. In all, 18 of those contacted agreed to participate, but due to availability, ultimately only 15 were interviewed. All interviewees were engaged in production in eastern England. The sample covered a range of agricultural cropping arrangements, including family-owned farms, large commercial estates, and contract farming. With regard to irrigated production, the majority of those interviewed concentrated on potatoes, with onions and/or carrots also important. Farm sizes ranged between 200 and 4,000 ha. The interviews were carried out between December 2017 and March 2018 and followed a themed question guide focusing on water risks, irrigation and technology, relationships with regulators, retailers and consumers, and how field vegetable production systems and supply chains are changing over time. The interviews featured a series of predominantly open-ended questions, and participants were encouraged to freely discuss the areas they considered to be of most interest and importance in greater depth and raise additional related issues according to their concerns. Interviews were audio-recorded with participants' consent, and recordings transcribed in full (redacted versions can be accessed here: 10.17862/cranfield.rd.12033651). Transcriptions were coded using qualitative analysis software, NVivo 11 (Gibbs, 2002) and analysed using a part-deductive part-inductive approach to thematic coding, where the researcher approached the data with a set of research questions and associated themes in mind, but remained open to the identification of new themes emerging from the dataset.

\subsection{Survey}

An online survey was built using Qualtrics (2018) software and posted between March and April 2018. A link to the survey was emailed to grower organisations and bodies who were asked to circulate it to their members or contacts. A survey link was also posted on two major 
grower websites. A total of 98 completed responses from field vegetable growers were received. Responses to the survey had a wider geographical coverage than the semistructured interviews, although an eastern England bias was still evident (41\% of responses). Thus, in comparison with the semi-structured interview sample, the questionnaire survey comprises views from growers based in areas that may be considered more water scarce (such as Norfolk and Suffolk), as well as views from those based in areas that may be considered to be less water scarce (such as North Yorkshire, Shropshire and Herefordshire). The bias towards eastern England that was nonetheless evident in the geographical distribution of responses probably illustrates a degree of self-selection fuelled by the greater interest that growers in areas at greater risk of water shortages take in irrigation. The survey was analysed statistically using SPSS (Allen and Bennett, 2010).

\subsection{Presentation of the results}

The results presented in what follows focus primarily on exploring how growers considered their production activities to be directly and/or indirectly exposed to the risk of water shortages and how they managed this. The strategies growers reported using to address these risks (along with promising strategies not currently employed), were analysed to elicit evidence about which features of resilience were being addressed. In the results, the factors discussed are those that received most attention during the semi-structured interviews with growers. As such, the paper does not present an exhaustive list of factors determining resilience to water shortages in agricultural production, but does illustrate the range of activities (and constraints) that growers predominantly consider as they determine their irrigation management practices. Qualitative findings stem from the semi-structured interview data, and where possible are supported with a verbatim quote. Results reported quantitatively, for example, by percentages, illustrate findings from the questionnaire data. For each issue discussed, the analysis considers the potential consequences for resilience at the catchment and supply chain scale (Table 1).

\section{Results and Discussion}

The results and discussions sections are structured as follows. Section 3.1 details the factors perceived to determine enterprise exposure and resilience to water shortages by the growers interviewed. Where possible these findings are supported by quantitative data from the questionnaire survey. Section 3.2 initially presents an academic conceptualisation of the relevant features of resilience, and following this, maps the findings presented in Section 3.1 to each of these. 
Every factor discussed in Section 3.1 is listed in Table 1 against the resilience features and dimensions that are discussed in Section 3.2. The influence of each factor on these features and dimensions is illustrated and linked implications for the wider catchment and supply chain are also indicated.

\subsection{Perspectives on factors determining system exposure and resilience to water shortages}

Water shortages (in particular, those due to abstraction restrictions) were perceived as a key and increasing production risk by most growers. All those interviewed, and the majority of survey respondents identified 'water shortages' as their primary water-related risk (59\%, $\mathrm{n}=98$ ), with most expressing greater consternation about abstraction restrictions than drought, per se, as the cause (67\% compared to $28 \%, \mathrm{n}=58$ ). Increasing concerns about water shortages can be understood in relation to interviewee narratives concerning the evolution of production risks over time. Growers highlighted the enormous pressure that tightening quality specifications (driven by retailers) now place on their irrigation decisions:

\section{They are. Yeah. They have cranked up. I'm so scared now of having a field that's full of [potato] scab and having to throw it all away. Participant $N$}

All pre-pack potatoes destined for the multiples (retailers) must meet stringent quality assurance standards, linked to shape, colour, size and skin finish. The risk of common scab on potatoes is triggered by insufficient soil moisture during tuber initiation (Lapwood and Hering, 1970) and is a key determinant of crop quality and major cause for concern emphasized by most interviewees. Growers also highlighted an intensified risk of financial losses due to increasing investments in production activities intended to maximise crop quality:

I mean if you have one bad year where a potato crop... not failed, but failed to meet specifications, or an onion crop, you'd be in serious trouble, just because of the amount of investment that has to go into that crop every year. Participant $E$

The proliferating financial riskiness of production was set against a backdrop of highly variable and unpredictable summer rainfall (characteristic of the UK climate) and a growing risk of exposure to extreme events due to climate change. This unpredictability was presented as a major barrier to implementing effective irrigation decision-making. The time required to move equipment around the farm often necessitates initiating irrigation applications well in advance of the timeframe over which rainfall can be forecast accurately. As such, irrigation decisions were presented as highly fraught and uncertain: 
You'll never get it right. In our climate you'll never get it right. That's why it is much easier to irrigate when it doesn't rain at all. Because you are much more certain. Participant $G$

\subsubsection{Access to water resources}

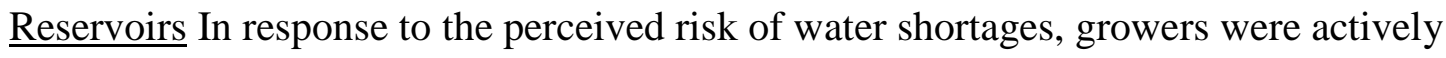
engaged in securing water supplies. As such, reservoirs featured strongly in grower accounts of resilience: "Building resilience is having the capacity to store high flow water to use in low flow periods." (Participant B). Growers strategically prioritised the use of water resources in reservoirs to buffer their main supply, carry headroom over into the next year, assert ownership over water in order to guarantee their ability to supply under contract ("I've already paid to pump it up there and it's mine", Participant A), and as insurance against unusually dry conditions. They were also favoured since growers have greater control in determining pumping rates (in contrast to direct abstraction). Moreover, they permitted farms to demonstrate more sustainable agricultural water management, given growing concerns around the negative environmental impacts of summer abstraction: "We have one or two winter reservoirs but we probably should do more. Yep. To be more politically correct, yes" (Participant C). Reflecting the notion of potential benefits for the environment, commentary on reservoirs painted winter abstraction and storage as a logical win-win strategy:

\footnotetext{
If we can switch some of this summer abstraction to winter abstraction that will potentially ease up the pressure on the whole system, because we are generally not watering over the winter so there's surplus water so we might as well capitalise on that and put it into reservoirs. Participant $D$
}

But several participants continued to prioritise irrigation from direct summer abstraction, despite having stored water available, in order to protect their licences (new regulations seek to reduce levels of 'unused' licensed water through revocation) and preserve storage capacity:
Sensibly, for the environment and everything else it's probably the worst thing we could do, isn't it? Because we are abstracting when we have no need to be. We could move it from other places, but we are trying to keep our permission. It's the way it's regulated. It seems to make sense to do it that way. Participant $H$

Participants also emphasized the high capital costs of reservoir construction, leading one participant to label them, "a really expensive insurance policy" (Participant G). Another considered that this mainly restricted reservoir-building to larger enterprises. Survey data supported this claim, with a higher percentage of enterprises with larger total land areas $(72 \%)$ indicating on-farm reservoir storage than smaller organisations $(46 \%, \mathrm{p}=.014)$. 
Reservoir ownership was also associated with larger irrigated areas $(\mathrm{p}=.002)$. A natural limit to the potential contribution of reservoirs to system resilience overall was also noted, due to increasing competition for winter abstraction as more reservoirs are built. One grower explained that their indecision over whether to install a reservoir was compounded by uncertainty about the storage volume needed to offset this risk:

We'll only get effectively high flow water, which, as more and more people access it, becomes more and more remote and more and more risky and less and less resilient, and therefore more and more costly. And therefore you have to have bigger and bigger reservoirs to mitigate that risk and... you can see where I'm getting to! Participant G

As such, lock-in to the acquisition of increasingly large reservoirs aligns with wider trends of agricultural expansion. Despite acknowledging the need for increasing storage to offset water risks, most enterprises only had reservoir capacity to cover production for a single season:

Most of the reservoirs around here are one season only. There is probably the odd one or two that would give the opportunity to go two years, but not many. Participant $B$

Few were prepared for a scenario (referred to as 'doomsday' by one participant) of two dry summers in a row with a dry winter in between. Reflecting this, only $18 \%$ of reservoirowning questionnaire respondents indicated having sufficient capacity to maintain production in a second year of drought.

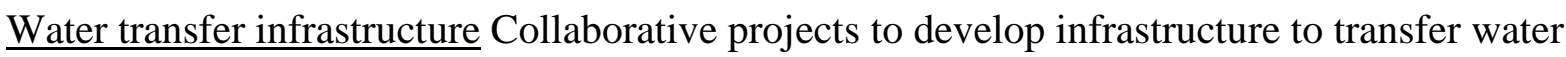
from areas of high supply to where it was needed for cultivation, both locally and regionally, were also highlighted by three participants as an important resilience-building strategy, although high costs were again noted.

You know, to my mind England is not a dry country at the current time. We've got an awful lot of water in the north west, in fact so much that farmers up there suffer. So there are ways and means of shipping water about. But it ain't going to come cheap, and resilience can be built in but we've got to understand the costs that may be involved, and consequently we will have to understand that food prices will rise a bit. Participant $B$

Whilst a few collaborative projects to divert water for agriculture were ongoing, negotiating multi-actor agreements was considered to be "fraught with difficulties", suggesting a need for greater social capital between rural landowners (Participant C).

Water trading Although not widespread (only $14 \%$ of respondents had traded water in the year prior to the survey) water trading was considered to hold potential for building resilience 
to water risks. For example, in over-licensed catchments ${ }^{1}$, the problem of non-irrigating landowners refusing to give up Licenses of Right could be addressed through "better, simpler, quicker trading arrangements" (Participant B). However, trading arrangements were felt to be cumbersome and lack flexibility, reflecting findings elsewhere (Rey et al., 2017). At present, whilst the regulator may relax restrictions on water trading by temporarily adopting a more flexible approach during exceptionally hot and dry summers, (as in 2018), such temporary actions do not remedy grower uncertainty about longer term water availability, which several participants complained limited their capacity to forward plan cropping programmes.

$\underline{\text { Rainwater harvesting and wastewater re-use Alternative (potentially valuable resilience) }}$ options for accessing water resources, such as harvesting rainwater or using wastewater, were also scarce amongst interviewees and survey respondents. None indicated re-use of wastewater, whilst very few harvested rainwater (only $8 \%$ of survey respondents had done so in the previous season). Interviewees voiced concerns over potential customer rejection of vegetables grown using recycled wastewater, and the volumes of rainwater that could be harvested from built infrastructure were minimal compared to the areas needing irrigation.

Er, that's going to be very tricky with protocols and the threat of contamination on a crop.

And to be honest, the wastewater, like roof runoff and things like that, it would only be a drop in the ocean. Participant $N$

\subsubsection{Irrigation application}

Equipment The resilience contribution of adopting more efficient technology was perceived to be complicated by cost and flexibility trade-offs. Growers predominantly continued to favour hose reels fitted with rain guns and booms, with little uptake of potentially more efficient technologies such as drip irrigation or centre-pivots. Survey data revealed heavy reliance on rain guns ( $86 \%$ of the sample, with $51 \%$ relying on them solely). Boom use was less common (36\%), whilst trickle and centre pivots or linear moves were only used by a minority (12\% and 7\%, respectively) and nearly always in conjunction with either rain guns, booms or both.

\footnotetext{
${ }^{1}$ i.e., catchments where, if existing licences were used to their full allocation, it would cause unacceptable environmental impact.
} 
Growers justified sustained preferences for rain guns in the context of supplemental irrigation, since irrigation may scarcely be required in a season with sufficient rainfall. When required, irrigation needs can be highly spatially variable. Growers therefore prioritise lower operating costs and greater flexibility despite lower water efficiency and high energy costs:

Guns and booms. Everything is either guns or booms. Drip irrigation is great, it's a much better way of irrigating a plant. But it's just the cost of it, the infrastructure you've got to put in for it and... you get a wet year and you mightn't even turn it on, you've still got the cost of laying all that tape, it's all single use, putting it all down. Whereas if it is wet the irrigators just stay in the shed. No one needs to move them so there's zero cost for that. Participant E

Pumping In terms of ongoing changes in water application, growers indicated greater involvement in modernising on-farm mains and pumping infrastructure and experimentation with different nozzle sizes. Several growers noted that their capacity to apply water could be limited in times of peak demand, and highlighted the potential efficiencies in terms of both labour and energy costs that could be achieved by changing pumping infrastructure, including the use of variable speed drive technology:
Yes, we've just brought a thousand metres of underground main in, so we will be at the point in 5 years' time where nearly all our farms will have a hydrant every 72 metres, so you don't have to use aluminium pipes across that. That might sound a silly thing, but if you've got a lot of guns to move, it's so efficient. Participant A

Scheduling Production system resilience was perceived as contingent on the accuracy of irrigation scheduling; growers thus often employed multiple scheduling technologies. The most common approaches included feeling the soil (69\%), using computerised scheduling services (48\%), and using in-situ soil water measurement equipment (37\%). Sixty-eight percent of respondents employed more than one method:

\footnotetext{
"I use combinations of neutron probes, we use the [capacitance probes]. We've got a lot of [capacitance probes]. And fork, spade, weather station, rain gauge, experience..." Participant $O$
}

Growers explained that using multiple scheduling methods assisted irrigation management decisions across increasingly large production areas:

\footnotetext{
You can't physically... you know... we don't just farm here, we are in a 30 mile radius. So you wake up in the morning and think "I wonder how much rain they have had over there". And to get in the car and go and have a look... Well there's times when we might have, oh,
} 
between thirty and forty irrigators going. And to manage that efficiently without help from some electronics, is a bit difficult. Participant A

\subsubsection{Water rights}

Abstraction regulation Ongoing abstraction reform, and the potential for reductions in 'headroom' (water allocation in excess of typical seasonal irrigation requirements), was described by one grower as "a challenge to resilience" (Participant J). As such, growers broadly resisted the threat of imposed water shortages by arguing for the preservation of licensed headroom. Some described taking actions to hinder regulatory efforts. Grower discourse queried how far the regulator can accurately quantify how much water the environment really needs: "If they are using the right criteria or not... that is a debate." (Participant F), and several participants presented aspects of licence regulation as nonsensical:

You have to question some of their water management a little bit when you see the river flooding and we are flooding water meadows, but then we can't pump at the same time.

Participant E

Issues were cited such as licences not permitting abstraction of high flows in summer or not permitting storage of water that would otherwise be discharged to the sea: "If it's come down in a sheet, and it's going to go straight out to sea, why can't we have it?" (Participant A). The regulator's planned approach to restrict future licensed volumes to a defined limit based on 'recent actual use' over a specified period (6 to 15 years reported), was presented as incentivising growers to find ways to use their full licensed allocation each year, even if this exceeded agronomic requirements:

\section{So at the back of my mind (and all the other abstractors, if they've got any sense, will be thinking the same) is in one of those six years, I've got to pump all of my water. Which makes irrigation really inefficient." Participant $O$}

This perspective was supported by survey data, with $72 \%$ of respondents agreeing that the approach drives growers to use irrigation water inefficiently to avoid their existing headroom being reduced. One interviewed grower also indicated that he chose to maintain multiple licenses to avoid simplifying the licence review process, "In theory it should be simplified. But my own cynical, personal view is, while it is so complicated it's easier to get them through" (Participant H). Another stated that if necessary, he would have no choice but to use 
water from an unlicensed reservoir, illustrating his perception that the financial risk of failing to meet quality specifications outweighed the risk of prosecution:

So I'd have to use it wouldn't I? And then I'd have to argue about it afterwards, because I couldn't wait for them to make a decision. Because when you are turning over ten million quid, which we do, I can't drop two or three million, can I? Participant C

Enhanced social networking around abstraction Despite rejecting the aspects of water governance discussed above, growers broadly applauded a shift by the regulator towards greater levels of collaboration with farmers. Frequency of communications, familiarity with staff and better lead-in times to plan for potential abstraction restrictions were all cited as contributing to a more resilient system for managing withdrawals:

We do have good relationships with the [regulator] now, you know 20 years ago they were like policeman, but they are not now, they do come and talk to us. Participant A

Water abstractor groups had formed in several areas, often in direct response to past water crises, permitting more effective engagement in water politics and co-ordination of catchment-wide voluntary abstraction reductions when critical water shortages were forecast (Leathes et al., 2003). Group membership was held by over half of those interviewed and a quarter of the survey respondents.

\subsubsection{Sales and the supply chain}

$\underline{\text { Switching to more drought tolerant cultivars Some participants highlighted the resilience }}$ value of changing to cultivars with greater scab resistance or greater water use efficiency. However, this was not a strategy that growers engaged in widely or frequently because uptake of new and less familiar cultivars by customers was considered to be limited. One grower reported that most retailers were loath to switch away from cultivars that had a good record of acceptability amongst consumers, even if these were not the most disease resistant cultivars available:

We are going for varieties that have more tolerance. The problem is getting them accepted by the customer. Participant $C$

Product specialisation Many growers described strategically increasing their focus on the production of high value crops: "We are looking to grow the highest value crop possible" (Participant N). Product specialisation was particularly acute where businesses operated largely as contractors (growing on rented land as part of another enterprise's rotation), with companies seeking to hone technical expertise and mechanical capacity on the production of 
a single crop. One participant discussed the greater risk of failure that such specialisation brought, indicating this was bound up with growing preferences for fixed price contracts:

As a kid, growing up on a farm, there was always one crop which did really well, there was always one crop which didn't do so well, but the average was good. These days costs dictate that every crop you grow has to do well. There's no sort of averaging, and certainly with us, that pressure is far more, because we are only one crop. As we've said, we can grow different types of that crop, to offset the risk a bit, but we've got no fallback. So having a contract, well at least we've got a known return if we hit the spec'. It's far less risky than the open market. Participant $P$

Specialisation in niche products such as salad potatoes, where conditions permitted, meant potentially higher profits, but also a greater risk of losses should water shortages affect production:

N: You know, the crop we grow is slightly different because we grow a lot of these salad potatoes, the small punnets we call them. If you had a crop of the larger ware and bakers (we used to grow more of those type), if they were scabby, there's usually a market for a processing job where the skins don't matter to the same degree. With these little salad potatoes, they are higher value, but lower yielding. If they've got scab, you can't...

Interviewer: You can't make chips out of them?

N: No, you can't make chips out of them. You could send them to a factory for processing and get them mashed up or whatever, but you don't get the yield and they are not really suitable for that. So you are left with a lot of money's worth that's gone wrong. And I don't want to take that risk.

The logistics for lifting and processing crops that meet stringent quality assurance criteria mean that once growers have invested in product specialisation, any deviation from anticipated production, processing and sales pathways entail a considerable financial loss. Whilst niche vegetables are often harvested early whilst small, and therefore consume less water, growers are more likely to capitalise on potential profits by successional crop production. For salad potatoes, successional crop production means that crops are at heightened scab risk throughout the production season, with growers more likely to overwater to control for this risk:

Yeah, okay, so I would suspect we are over-watering as far as growth is concerned at the early stages of most of our potatoes, because we are definitely watering for quality rather than growth, you know rather than size or yield at that point. And so probably we... water 
is being wasted to promote quality, rather than the mass that you eat when you get it at the end. Participant $C$

\subsubsection{Fixed price contracts}

Most growers interviewed indicated a strong preference for selling their produce under fixed price contracts, and over half $(51 \%)$ of the survey respondents grew more than $75 \%$ of their planted area under these terms. This strategy was perceived as a way to reduce exposure to market price volatility and enhance financial stability to hedge against the increasingly sizeable losses that larger enterprises can be exposed to:

Because basically everybody thinks that the open market situation is too risky. So either you make a hatful of money, or you lose a hatful of money. Or potentially you do. So people are going away from that and more and more to these fixed price contracts. Participant $G$

However, fixed price contract terms constrain production within a tighter specification range, increasing the potential negative impacts of insufficient watering. Growers noted that this incentivised greater irrigation applications than had historically been the case:

And the crucial thing at that time, or the difference between then and now, see you needed to water to make sure you had a crop to harvest, that hasn't changed, but what has changed is we are trying to create quality, and you don't get any quality without lots of water Participant A

Growers also noted that it was becoming increasingly difficult to break into new marketing relationships or to find alternative sales channels for produce:
At the end of the day, most packers have their existing growers, and yes if they get a new contract then they'll sort of cast out beyond their standard grower base, but it is very much a closed circuit of growers generally for each one. Participant $K$

Auditing for quality assurance Participation in audit schemes was another feature of contemporary produce sales with implications for business resilience. Audits were regarded as an inevitable, if regrettable, aspect of contemporary marketing arrangements:

\footnotetext{
I accept they're a part of growing crops, I'm not complaining about them. But we don't need more restraints. Participant $N$
}

One interview participant explained that participation in a particular audit scheme permitted the sale of produce at higher prices, but most emphasised instead the additional labour costs of this bureaucratic "tick box exercise" (Participant E). Several participants discussed the additional administrative pressure audits placed on enterprises and two noted that this could 
be a contributing factor to decisions by landowners to leave farming. Although participants indicated that audits collect some details about water use and irrigation efficiency, retailers were perceived to only genuinely care about produce quality, with the attention paid by audits to efficient and sustainable water use considered little more than "lip service" (Participant D).

\subsubsection{Management, staffing and reinvestment}

Human capital for irrigation Grower accounts highlighted the importance of both passion and skill in managing irrigation to enhance production system resilience to water shortages.

I have a very hands on approach to irrigation. I'm probably far more passionate than many others, and I think individual input in management helps a lot in that respect. Participant $K$

Participants indicated that they sought to employ staff who would be dedicated to undertaking irrigation tasks as accurately and promptly as possible, but noted that staff did not typically recognise the key importance of irrigation:

Generally, speaking, moving irrigators on some of the farms is a secondary job to the main role that that person may have, and they won't receive much training, (although they will have received some) and they won't understand themselves the implications of getting it wrong, or the benefits of getting it right. Participant $B$

The limited availability of farm labour was considered to constrain the attentiveness of workers to crop water needs: "I mean in the UK we haven't got the staff to be in crops" (Participant B). Consequently, reserves of irrigation skill and expertise are highly concentrated in the hands of farm managers, who represent key stocks of human capital where experiential knowledge, information processing and decision-making power converge in the irrigation system:

I'm just basically the server. I take information from whoever inputs it into me and then I just push it to wherever. Participant $M$

$\underline{\text { Reinvesting for success }}$ Growers strongly emphasized that reinvestment to enhance technical production capacities rather than diversification to other economic pursuits was considered essential for enterprises to remain competitive.

Wherever you go, farms that are doing well are farms that are reinvesting. They are not farms that are taking the money and running, or taking the money and just letting it tick over and taking the money and letting it tick over, the farms that are doing well are the ones that are using the money that they are making and reinvesting it in new technology. Participant $B$ 
Some growers highlighted the importance of investing in highly visible assets which could bolster customer confidence in production abilities:

I mean where we are sitting now, I put this up two years ago which was a huge investment, all this line of buildings, and the concrete and all the bits that go with it. But they put you on the map a bit, and it helps us with our contracts. If Tesco's or Marks and Spencer's come here they see it's a professional outfit. Participant A

However, several growers discussed the fact that the extreme level of pressure on farm managers during the growing season limited capacity for experimentation:

If I start focussing on a small area of novel crop and I take my eye off the ball with my core business, you know, this could all go wrong. That ain't going to make any money for another ten years, so I'm slightly nervous of doing that. Participant $D$

\subsection{How do factors identified by growers map onto key resilience attributes?}

Many of the factors growers discussed relate to the concept of headroom, either in water resources, financial buffers, or even mental headspace for experimentation and planning. Whilst growers recognised the importance of saving space for resilience, their ability to do so was constrained by processes (quality specification, auditing, fixed price contracting and specialisation) they had to engage in to access sales channels. Capacity for resilience was also reported to be limited by equipment, infrastructure and labour availability, all of which are currently determined by cost efficiency considerations. Growers reported efforts to increase safety nets to guard against potential irrigation failures (employing multiple scheduling methods, accessing additional water sources, and sustaining flexibility in their irrigation application methods). However, greater investment in the production of fewer produce types to meet tighter quality standards was acknowledged to expose production systems to a greater degree of risk from water shortages than in the past.

A wide range of different elements have been attributed to agrifood system resilience (Stone and Rahimifard, 2018), although the inherent complexity of agricultural production systems makes determining strictly defined indicators problematic (Darnhofer et al., 2010; Cabel and Oelofse, 2012). Based on the grower accounts described above, three common criteria for assessing resilience (redundancy, diversity and autonomy to reorganise) have been selected for analysis. The ways in which the resilience strategies and limitations described contribute to three key dimensions of resilience (persistence, adaptability and transformability) are discussed, as well as how the factors determining resilience in production systems affect the 
catchments and supply chains in which they are nested. Table 1 illustrates the implications of the different factors discussed by growers for these two closely related systems as well as identifying their contributions to the resilience elements and dimensions outlined above.

\subsubsection{Academic understandings of redundancy, diversity and autonomy to reorganise}

Redundancy and diversity contribute to resilience by ensuring that if a system component fails, another is available that can substitute (Cabel and Oelofse, 2012). Diversity refers to a range of different types of resource which provide functional overlap or reinforcement (Allison and Hobbs, 2004), whilst redundancy refers to spare capacity (surplus, headroom or a buffer) in one type of resource to permit normal activities to continue in the face of a disturbance (Stone and Rahimifard, 2018). Whilst both redundancy and diversity enhance system resilience (especially robustness or the capacity to persist), by, for example, reducing output volatility in response to fluctuations in resource availability, this comes at the cost of efficiency, requiring an investment that may not provide additional mean returns (Cabel and Oelofse, 2012; Abson et al., 2013).

Capacity to reorganise either in response to, or in anticipation of, disruptions is also common in definitions of resilience from the social-ecological systems literature, and often regarded as dependent on autonomy (Carpenter et al., 2001; Folke, 2006). Authors have noted that interdependence between local institutions (such as farms) and collective action within social networks contributes to system capacity to flex in response to rapidly changing environments (Cabel and Oelofse, 2012; Urruty et al., 2016). As such, the nature of connectedness between system components has important implications for resilience. Many weak connections are considered to enhance capacity for reorganisation, whilst the presence of few, strong connections may limit resilience by increasing rigidity in the system (Cabel and Oelofse, 2012; Rotz and Fraser, 2015).

Taken together, redundancy, diversity and autonomy to reorganise determine how flexible systems can be in their responses to, and preparations for, shocks and stresses.

\subsubsection{Redundancy in the growers' narrative accounts}

Growers were acutely aware of the need for buffer resources in both their water supplies and finances which could help maintain stability despite potential water shortages (and other shocks). Participants sought to preserve headroom in available water in order to mitigate the negative impacts of abstraction restrictions on crop yield and quality (Participant $\mathbf{J}$ ), enhance their business's odds of survival should they experience a run of dry years (Participant A) and 
keep options open regarding future production expansion (Participant D). To this end growers argued against processes of abstraction reform and invested in reservoirs. Other strategies by which redundancy in water availability could be enhanced were raised in discussions, but were less common for a variety of reasons (high costs and the complexity of striking multiactor agreements for water transfer schemes; concerns about potential food safety issues for wastewater re-use; an unsupportive regulatory environment for water trading; and limited consumer acceptability of more water-efficient cultivars).

In addition to redundancy in water resources, most growers also planned a contingency in their production volume (usually of around 15\%), to permit an expected degree of crop failure, and all sought to achieve a financial buffer (profit) which would allow for reinvestment (perhaps in building resilience to future water shortages). However, several growers stated their capacity to achieve either goal was increasingly limited by longer term background food price deflation. The widespread adoption of fixed price contracts to guard against financial losses due to price volatility precluded the possibility of making significant financial gains. Redundancy was also constrained in accounts of managerial workloads ("It's just crazy, you work like hell just to stand still”, Participant A), as well as farm labour availability for moving irrigators, and in office staff capacity for processing increasingly demanding audits.

Despite efforts to preserve redundancy by various means, maintaining supplies of resources that exceed what is needed to meet output goals under normal conditions entails costs (Darnhofer et al., 2010). Given this trade-off, growers seek to strike a balance that permits robustness to water shocks, whilst not pricing themselves out of the market. At present, however, growers face pressures from both retail and regulatory bodies to reduce redundancy in order to maximise efficiency (by minimising both agricultural water use and the costs of production), even as, paradoxically, customer quality demands drive greater irrigation applications. Ongoing processes of enterprise expansion (driven by tightening quality specifications, increasing supply system connectivity and declining sales prices) all limit opportunities for slack in the system. Whilst detrimental to the resilience of the production system to water shortages and other shocks, prioritising efficiency to maximise financial returns is essential for growers who wish to operate successfully in the near term. 


\subsubsection{Diversity in the growers' narrative accounts}

Diversity is a widely acclaimed resilience strategy, with diversity in function, not just type, particularly noted (Kahiluoto et al., 2014). However, the loss of diversity within agricultural production systems (most notably, biological and genetic diversity, but also in terms of suppliers, staff and customers), has been highlighted by many as a critical problem linked to specialization and the exit of smaller agricultural enterprises from production (Rotz and Fraser, 2015; Stone and Rahimifard, 2018).

In comparison with undertakings that contributed to production system redundancy, actions to increase system diversity featured less prominently in the accounts growers gave of their irrigation management practices. Efforts were evident where they sought to maintain multiple licenses, gain additional water access (combining summer abstraction with reservoirs), and employ multiple scheduling technologies. Whilst prioritising direct summer abstraction for irrigation despite having reservoir water available may damage catchment aquatic health, growers felt it ensured against having summer licenses revoked, thereby retaining their access to a diversity of water options. The use of a diversity of scheduling methods permits greater confidence in the accuracy of irrigation decisions, which seeks to limit the risk that irrigation issues might be overlooked as land to staff ratios rise due to enterprise expansion.

As with redundancy, diversity trades off against efficiency. As such, despite the efforts of growers to retain diversity where possible, market and regulatory pressures made this difficult. To achieve ever greater efficiencies, producers face incentives to specialise in producing a smaller range of crop types over larger areas, leading to declining landscape heterogeneity and crop and genetic diversity (Lin, 2011; Rotz and Fraser, 2015). The market presents growers with a narrow range of sales options in a market-place dominated by a few powerful players. These factors increase the risk that non-uniform produce of varying quality will be unsaleable, which amplifies the potential risk of water shortages.

\subsubsection{Autonomy to reorganise in the growers' narrative accounts}

Growers strategically sought to preserve and enhance their autonomy to reorganise production via several means. The decision to maintain the use of guns and booms, rather than switching to more efficient irrigation technology, retains flexibility and permits autonomous farm level adjustment to variable seasonal requirements. Some growers reported investing in infrastructure to facilitate rain gun use, revealing a strong commitment to this type of irrigation technology. Reservoirs also facilitate greater autonomy for growers, 
permitting more control over the rate and timing of water use than direct abstraction. At the intra-farm level, participants reported engaging in social networking with other growers and regulators, evidenced in the development of water abstractor groups that permit co-ordinated abstraction reductions, enhancing adaptability within catchments. Water trading could also permit the autonomous redistribution of water resources between growers, although it was not considered to be supported by the current regulatory environment.

Nevertheless, growers highlighted that their autonomy and flexibility was highly constrained by processes that accompany contemporary sales and marketing arrangements: specialisation in higher value products, fixed-price contracts and audit requirements. Despite limiting growers' capacities to change course by reconfiguring resource use or sales pathways in response to water shortages, the majority of growers perceived the financial risk of not engaging with these sales and marketing arrangements to outweigh other resilience considerations in the short term.

\subsection{What are the impacts on catchments and supply chains?}

Resilience is a multi-scalar concept (Folke et al., 2010). Considering the resilience of systems in isolation from linked impacts on other, inter-related systems can lead to false conclusions about the sustainability of the system of interest. Water management within field vegetable production systems has implications in particular for the catchments from which water is withdrawn (and to which it may be returned), and also for the supply chains through which produce travels, whilst feedback from each may in turn impact the production system.

Some actions undertaken by growers to enhance resilience stood to benefit both the catchment (by reducing the potential for over-abstraction) and the supply chain (by enhancing the stability of the output of quality produce). Storing winter or high-flow water in reservoirs (provided its use is prioritised over direct abstraction when demand is high); social networking to facilitate abstraction regulation and water-trading; adopting water efficient cultivars; and accurate irrigation scheduling are likely to have positive impacts on both related systems (Table 1). Policies which support grower capacity to engage in these resilience strategies would therefore be helpful. However, trade-offs between costs and benefits to catchments and the supply chain were noted, particularly where quality and cost efficiency considerations applied. Growers sought to preserve headroom in their licences despite the potential negative impacts of collective over-licensing on catchment health. In order to achieve stable and profitable sales, growers adopted fixed price contracts and 
specialised in the production of higher value produce despite associated higher water demands. Likewise, growers limited production costs by maintaining less efficient application methods, despite the increased the risk of over-applying irrigation. As such, where benefits to catchments and the supply chain were at odds, grower responses unilaterally prioritised supply chain benefits over catchment health (Table 1).

\subsection{Dimensions of resilience: Persistence, adaptability and transformability}

The concept of social-ecological resilience combines withstanding disturbance with embracing change (Helfgott, 2018). It has been increasingly recognised that for a system to be resilient it must go beyond maintaining performance in the face of input variability (which can be referred to as robustness or persistence). Resilient systems must also incorporate capacity for reconfiguration, renewal and learning (adaptability), and ultimately, the potential for radical shifts in trajectory (transformation) (Folke et al., 2010; Ashkenazy et al., 2018). An unwillingness to invest in preparations for uncertain, longer term risks means that, in many social-ecological systems, efforts to enhance resilience have focussed on robustness for persistence rather than adaptation and transformation (Boltz et al., 2019). However, robustness is a performance measure with clearly specified parameters (Anderies et al., 2013), beyond which a sizeable enough shock will inevitably cause damage. High uncertainty and complexity in risk exposure due to global environmental change means we cannot discount the possibility of future shocks exceeding established parameters in sub-systems such as field scale agriculture. Grower discussions of their attempts to introduce redundancy into their production systems via reservoir installations signalled this trouble when difficulties around determining necessary volumes were highlighted.

Whilst redundancy, diversity and autonomy to reorganise may each contribute to any of the three resilience dimensions being considered, redundancy and diversity primarily enhance system capacity to resist change (Giannoccaro et al., 2018). In grower accounts, strategies to enhance redundancy and diversity were emphasised, illustrating a strong managerial focus on robustness. Adaptability was limited due to declining autonomy and flexibility on a number of fronts. Despite a need to improve capacities for projecting, planning and managing for transformation (Boltz et al., 2019), grower accounts revealed little room for doing so. In higher risk production environments, fuelled by stringent quality demands and enterprise expansion, growers highlighted the need for a closer focus on the management of day to day 
production activities. They emphasised that uncertainty around shifting water regulations and wider political short-termism limited their capacity to plan and prepare for the longer term.

\subsection{Implications for the sustainability of UK irrigated agriculture in the short and longer} term?

Limits on redundancy, diversity and autonomy for reorganisation are linked to declining flexibility and increasing system connectivity in which the activities of a diminishing number of actors and enterprises become increasingly regimented. The prioritisation of production stability in this increasingly rigid system determines a weighting towards robustness and persistence whilst adaptability and transformability are restricted (Table 1). However, despite managerial preferences for enhancing robustness, capacity to do so is limited by the doctrine of efficiency. This places UK field vegetable production somewhere between the exploitation and conservation phase of an adaptive cycle (Carpenter et al., 2001), wherein connectedness and stability are increasing and capital is slowly accumulated. This finding reflects conclusions drawn in studies of conventional agriculture elsewhere (Allison and Hobbs, 2004). Resilience scholars highlight the danger of falling into a 'rigidity trap' at this point (Carpenter and Brock, 2008), as increasing system controls limit flexibility and increasing system resource efficiency depletes reserves for absorbing or adapting to water shocks. 'Negative resilience' can be used to describe this system state, since the system exhibits increasing robustness, yet a decreasing capacity for change (Allison and Hobbs, 2004). However, in accordance with resilience theory, directional travel at this stage of the adaptive cycle brings systems ever closer to thresholds beyond which collapse and reconfiguration are inevitable (Carpenter et al., 2001). It is thus crucial that growers employ strategies which build capacities for adaptation and transformation, so that system shifts can be guided in desirable, rather than undesirable, directions.

\section{Conclusions}

This paper has explored grower reports of the factors determining the resilience of their field vegetable production systems to water shortages. The analysis has shown how, via strategies to enhance redundancy and diversity within their production systems (and, with a particular focus on maintaining headroom in their water allocations), growers attempt to reduce their exposure to the negative impacts of water shortages and maintain a robust and stable output of saleable produce. These strategies predominantly enhance the persistence dimension of resilience. At the same time, there was some evidence of increasing investment in social 
networks around water abstraction, which enhances adaptability. Nevertheless, grower attempts to achieve resilience were highly constrained by market and regulatory factors which reduce their autonomy to reorganise system components and necessitate everincreasing cost and resource efficiencies, driving out space for redundancy and diversity. Growers were more focussed on robustly maintaining their outputs than on enhancing adaptability or transformability. But robustness strategies have natural limits in terms of their contribution to resilience. Where a robust performance permits the accrual of profit, attainment of a financial buffer may enhance capacity to adapt and transform. However interviewed growers emphasized that reinvesting profits in honing the efficiency of their current production performance was an essential strategy for successful businesses and voiced concerns that investing time and money in diversifying to alternatives could put the mainstay of their business at risk. As such, the pressures of the highly competitive financial environment in which growers are currently operating (in addition to a regulatory and political environment characterised by uncertainty and short-termism) enforces a focus on near-term efficiency whilst opportunities are missed for building resilience to water shortages over the longer term in preparation for adjustment to an increasingly extreme and volatile climate.

The imbalance in production-level approaches to building resilience to water-related risks that has been revealed by the reported findings is likely to stem from the asymmetrical power relations that characterise the food system, wherein the market is dominated by a limited number of very powerful retailers, who are able to squeeze producer prices whilst imposing exacting quality demands. This power imbalance was evident in the fact that, when growers must choose between strategies that trade off benefits between catchments and the supply chain, the interests of the latter are consistently prioritised. Field vegetable producers undertake irrigation management decisions within the context of conflicting demands to optimise efficiencies both in terms of water use, and in terms of the costs of production, whilst achieving high quality outputs that meet an ever-narrowing range of specifications. Specialisation and expansion offer growers the efficiencies needed to produce high quality vegetables at very low prices, but lock the production system onto path-dependent trajectories where diversity and redundancy are replaced by connectivity and rigidity. These pressures and pathways prevent growers from undertaking strategies that could enhance transformative capacity in farm enterprises, which, in combination with the crystallisation of power 
structures in the supply chain, contributes to an agrifood system that increasingly exhibits a state of lock-in or negative resilience.

\section{Acknowledgement}

We are grateful for support from the growers who engaged in the interviews, the respondents to the online survey and organisations who helped support data collection. This research was funded through the Global Food Security's 'Resilience of the UK Food System Programme', with support from the Biotechnology and Biological Sciences Research Council, Economic and Social Research Council, Natural Environment Research Council and Scottish Government (BB/N020499/1).

\section{References}

Abson, D. J., Fraser, E. D. G. Benton, T. G. (2013) 'Landscape diversity and the resilience of agricultural returns: A portfolio analysis of land-use patterns and economic returns from lowland agriculture', Agriculture and Food Security, 2(1). doi: 10.1186/2048-7010-2-2. Allen, P. J. and Bennett, K. (2010) PASW statistics by SPSS: a practical guide: version 18.0. Cengage Learning.

Allison, H. E. and Hobbs, R. J. (2004) 'Resilience, adaptive capacity, and the "lock-in trap" of the Western Australian agricultural region', Ecology and Society, 9(1). doi: 10.5751/ES00641-090103.

Anderies, J. M., Folke, C., Walker, B. and Ostrom, E. (2013) 'Aligning Key Concepts for Global Change Policy: Robustness, Resilience, and Sustainability', Ecology and Society, 18(2), p. 16. doi: 810.5751/es-05178-180208.

Ashkenazy, A., Calvão Chebach, T., Knickel, K., Peter, S., Horowitz, B. and Offenbach, R. (2018) 'Operationalising resilience in farms and rural regions - Findings from fourteen case studies', Journal of Rural Studies, 59, pp. 211-221. doi: 10.1016/j.jrurstud.2017.07.008. Boltz, F., LeRoy Poff, N., Folke, C., Kete, N., Brown, C. M., St. George Freeman, S., Matthews, J. H., Martinez, A. and Rockström, J. (2019) 'Water is a master variable: Solving for resilience in the modern era', Water Security, 8(May). doi: 10.1016/j.wasec.2019.100048. Brown, I., Thompson, D., Bardgett, R., Berry, P., Crute, I., Morison, J., Morecroft, M., Pinnegar, J., Reeder, T. and Topp, K. (2016) 'Chapter 3: Natural environment and natural assets', UK Climate Change Risk Assessment 2017: Evidence Report. Available at: 
https://www.theccc.org.uk/wp-content/uploads/2016/07/UK-CCRA-2017-Chapter-3-Naturalenvironment-and-natural-assets.pdf.

Cabel, J. F. and Oelofse, M. (2012) 'An indicator framework for assessing agroecosystem resilience', Ecology and Society, 17(1). doi: 10.5751/ES-04666-170118.

Carpenter, S. R. and Brock, W. A. (2008) 'Adaptive capacity and traps', Ecology and Society. doi: 10.5751/ES-02716-130240.

Carpenter, S., Walker, B., Anderies, J. M. and Abel, N. (2001) 'From Metaphor to Measurement: Resilience of What to What?', Ecosystems, 4(8), pp. 765-781. doi: 10.1007/s10021-001-0045-9.

Darnhofer, I., Fairweather, J. and Moller, H. (2010) ‘Assessing a farm’s sustainability: Insights from resilience thinking', International Journal of Agricultural Sustainability, 8(3), pp. 186-198. doi: 10.3763/ijas.2010.0480.

Defra (2011) Water Usage in Agriculture and Horticulture. Results from the Farm Business Survey 2009/10 and the Irrigation Survey 2010. Available at:

https://webarchive.nationalarchives.gov.uk/20130125180121/http://www.defra.gov.uk/statisti cs/files/defra-stats-foodfarm-farmmanage-fbs-waterusage20110609.pdf.

Defra (2016) Horticulture Statistics 2015.

Folke, C. (2006) 'Resilience: The emergence of a perspective for social-ecological systems analyses', Global Environmental Change-Human and Policy Dimensions, 16(3), pp. 253267. doi: 10.1016/j.gloenvcha.2006.04.002.

Folke, C, Carpenter, SR, Walker, B, Scheffer, M, Chapin, T, Rockstrom, J (2010) Resilience thinking: integrating resilience, adaptability \& transformability Ecology and Society, 15(4), 9. Giannoccaro, I., Massari, G. F. and Carbone, G. (2018) 'Team resilience in complex and turbulent environments: The effect of size and density of social interactions', Complexity, 2018. doi: 10.1155/2018/1923216.

Gibbs, G. R. (2002) Qualitative data analysis: Explorations with NVivo. Open University. Hanjra, M. A. and Qureshi, M. E. (2010) 'Global water crisis and future food security in an era of climate change', Food Policy. Elsevier Ltd, 35(5), pp. 365-377. doi: 10.1016/j.foodpol.2010.05.006.

Hess, T.M., Knox, J.W., Kay, M.G., and Weatherhead, E.K. (2010). Managing the Water Footprint of Irrigated Food Production in England and Wales. In Hester, R.E. and Harrison, 
R.M. (Eds) Issues in Environmental Science and Technology 31: Sustainable Water. pp.185. ISBN: 9781849730198.

Helfgott, A. (2018) 'Operationalising systemic resilience', European Journal of Operational Research. Elsevier B.V., 268(3), pp. 852-864. doi: 10.1016/j.ejor.2017.11.056.

HMRC (2017) UK Overseas Trade Statistics, Data by Commodity Code. HM Revenue \& Customs.

Kahiluoto, H., Kaseva, J., Hakala, K., Himanen, S. J., Jauhiainen, L., Rötter, R. P., Salo, T. and Trnka, M. (2014) 'Cultivating resilience by empirically revealing response diversity', Global Environmental Change, 25(1), pp. 186-193. doi: 10.1016/j.gloenvcha.2014.02.002. Knox, J. W., Hurford, A., Hargreaves, L. and Wall, E. (2012) Climate Change Risk Assessment for the Agriculture Sector. Defra Project Code GA0204. London.

Knox, J. and Hess, T. (2017) 'Advances in irrigation management and technology in potato cultivation: experiences from a humid climate', in Wale, S. (ed.) Achieving sustainable cultivation of potatoes Volume 2 - Production and storage, production and sustainability. Burleigh Dodds, pp. 69-88. doi: 10.19103/AS.2017.0031.05.

Knox, J.W., Kay, M.G., Holman, I.P., and Hess, T.M. (2020) 'Irrigation water strategy for UK agriculture and horticulture', $14 \mathrm{pp}$. Cranfield University.

Knox, J.W., Hess, T.M., Morris, J (2018) Identifying trade-offs and reconciling competing demands for water: Integrating agriculture into a robust decision-making framework. Earth's Future, 6(10): 1457-1470.

Lapwood, D.H. and Hering, T.F. (1970) Soil moisture and the infection of young potato tubers by Streptomyces scabies (common scab). Potato Research, 13(4), pp. 296-304. Leathes, W, Knox, J.W., Kay, MG., Trawick, P., Rodriguez-Diaz, JA. (2008). Developing UK farmers' institutional capacity to defend their water rights and effectively manage limited water resources. Irrigation and Drainage, 57(3), pp. 322-331.

Lin, B. B. (2011) 'Resilience in Agriculture through Crop Diversification: Adaptive Management for Environmental Change', BioScience, 61(3), pp. 183-193. doi: 10.1525/bio.2011.61.3.4.

Merriam-Webster (2020) Resilience, Dictionary, Merriam-Webster.com. Available at: https://www.merriam-webster.com/dictionary/resilience. (Accessed: 19 March 2020). 
Olsson, L., Jerneck, A., Thoren, H., Persson, J. and O'Byrne, D. (2015) 'Why resilience is unappealing to social science: Theoretical and empirical investigations of the scientific use of resilience', Science Advances, 1(4), pp. 1-12. doi: 10.1126/sciadv.1400217.

Qualtrics (2018) 'Qualtrics’. Provo, Utah, USA.

Rey, D., Holman, I. P., Daccache, A., Morris, J., Weatherhead, E. K. and Knox, J. W. (2016) 'Modelling and mapping the economic value of supplemental irrigation in a humid climate', Agricultural Water Management 173, pp. 13-22. doi: 10.1016/j.agwat.2016.04.017.

Rey, D., Holman, I. P. and Knox, J. W. (2017) 'Developing drought resilience in irrigated agriculture in the face of increasing water scarcity', Regional Environmental Change. Springer Berlin Heidelberg, 17(5), pp. 1527-1540. doi: 10.1007/s10113-017-1116-6. Rotz, S. and Fraser, E. D. G. (2015) 'Resilience and the industrial food system: analyzing the impacts of agricultural industrialization on food system vulnerability', Journal of Environmental Studies and Sciences, 5(3), pp. 459-473. doi: 10.1007/s13412-015-0277-1. Salmoral, G., Rey, D., Rudd, A., de Margon, P. and Holman, I.P (2019) ‘A Probabilistic Risk Assessment of the National Economic Impacts of Regulatory Drought Management on Irrigated Agriculture', Earth's Future. Cranfield Water Science Institute (CWSI), Cranfield University, Cranfield, United Kingdom, 7(2), pp. 178-196. doi: 10.1029/2018EF001092. Stone, J and Rahimifard, S (2018) Resilience in agri-food supply chains: a critical analysis of the literature and synthesis of a novel framework Supply Chain Management, 23, 207-238. Urruty, N, Tailliez-Lefebvre, D., Huyghe, C. (2016) Stability, robustness, vulnerability and resilience of agricultural systems: a review Agron for Sustainable Development 36(1) 1-15. 
Table 1 Contributions of the resilience factors discussed to different features and dimensions of resilience and their implications for closely related systems. Direction of arrows indicate positive and negative impact; bi-directional arrows indicate a combined impact.

\begin{tabular}{|c|c|c|c|c|c|c|c|c|c|}
\hline Resilience factor & Extent & Redundancy & Diversity & $\begin{array}{l}\text { Autonomous } \\
\text { reorganisation }\end{array}$ & Persistence & Adaptability & Transformability & Catchment & $\begin{array}{c}\text { Supply } \\
\text { chain }\end{array}$ \\
\hline $\begin{array}{l}\text { Preserve allocation } \\
\text { headroom }\end{array}$ & $\begin{array}{l}\text { Widespread (with limited } \\
\text { success) }\end{array}$ & $\uparrow$ & & & $\uparrow$ & & & $\downarrow$ & $\uparrow$ \\
\hline $\begin{array}{l}\text { Abstraction social- } \\
\text { networking }\end{array}$ & $\begin{array}{l}\text { More common in water } \\
\text { scarce areas and amongst } \\
\text { larger enterprises }\end{array}$ & & & $\uparrow$ & & $\uparrow$ & & $\uparrow$ & $\uparrow$ \\
\hline On-farm reservoirs & $\begin{array}{l}\text { Widespread in water } \\
\text { scarce areas and amongst } \\
\text { larger enterprises }\end{array}$ & $\uparrow$ & $\uparrow$ & $\uparrow$ & $\uparrow$ & & & $\uparrow$ & $\uparrow$ \\
\hline Water recycling & Limited & $\uparrow$ & & & $\uparrow$ & & & $\uparrow$ & $\uparrow$ \\
\hline $\begin{array}{l}\text { Water transfer } \\
\text { infrastructure }\end{array}$ & Limited & $\uparrow$ & & & $\uparrow$ & & & $\uparrow$ & $\uparrow$ \\
\hline Water trading & Limited & & & $\uparrow$ & & $\uparrow$ & & $\uparrow$ & $\uparrow$ \\
\hline $\begin{array}{l}\text { Maintaining guns and } \\
\text { booms }\end{array}$ & Widespread & & & $\uparrow$ & & $\uparrow$ & & $\downarrow$ & $\uparrow$ \\
\hline $\begin{array}{l}\text { Modernising pumping } \\
\text { systems and switching } \\
\text { nozzles }\end{array}$ & $\begin{array}{l}\text { Widespread in water } \\
\text { scarce areas }\end{array}$ & $\uparrow$ & & & $\uparrow$ & & & $\uparrow$ & $\uparrow$ \\
\hline $\begin{array}{l}\text { Multiple scheduling } \\
\text { methods }\end{array}$ & $\begin{array}{l}\text { Widespread in water } \\
\text { scarce areas }\end{array}$ & $\uparrow$ & $\uparrow$ & & $\uparrow$ & & & $\uparrow$ & $\uparrow$ \\
\hline Fixed price contracts & Widespread & & & $\downarrow$ & $\uparrow$ & $\downarrow$ & & $\downarrow$ & $\uparrow$ \\
\hline Auditing & Widespread & & & $\downarrow$ & $\uparrow$ & $\downarrow$ & & $\uparrow$ & $\uparrow$ \\
\hline $\begin{array}{l}\text { Specialising in high } \\
\text { value products }\end{array}$ & $\begin{array}{l}\text { Widespread in water } \\
\text { scarce areas }\end{array}$ & $\uparrow$ & $\downarrow$ & $\downarrow$ & $\uparrow$ & $\downarrow$ & & $\downarrow$ & $\uparrow$ \\
\hline $\begin{array}{l}\text { Switching to less thirsty } \\
\text { cultivars }\end{array}$ & Limited & $\uparrow$ & & & $\uparrow$ & & & $\uparrow$ & $\uparrow$ \\
\hline $\begin{array}{l}\text { Human capital for } \\
\text { irrigation }\end{array}$ & Limited & $\downarrow$ & & $\downarrow$ & $\uparrow$ & & & $\uparrow$ & $\uparrow$ \\
\hline $\begin{array}{l}\text { Reinvesting in } \\
\text { production }\end{array}$ & $\begin{array}{l}\text { Widespread within } \\
\text { competitive businesses }\end{array}$ & $\uparrow$ & & & $\uparrow$ & & $\downarrow$ & $\uparrow$ & $\uparrow$ \\
\hline
\end{tabular}

Note: Text and arrows in grey indicate resilience factors that are currently limited in the extent to which they operate. 